\title{
JARINGAN KOMUNIKASI "INOVASI BERAS SEHAT"
}

\author{
Luluk Ilma Kusumadewi ${ }^{1}$, Dwiningtyas Padmaningrum ${ }^{2}$, Bekti Wahyu Utami ${ }^{3}$ \\ ${ }^{1,2,3}$ Fakultas Pertanian, Jurusan Penyuluhan dan Komunikasi Pertanian, Universitas Sebelas Maret \\ Jl. Ir. Sutami No. 36A Kentingan, Surakarta, Jawa Tengah, Indonesia, 57126 \\ No. Telp./HP: ${ }^{1} 082133809600,{ }^{2,3}(0271) 637457$ \\ E-mail: 1'klulukilma@gmail.com, ${ }^{2}$ arumyunus@gmail.com, ${ }^{3}$ uut_ay@yahoo.com
}

Naskah diterima pada tanggal 17 Januari 2019, direvisi tanggal 2 April 2020, disetujui 13 April 2020.

\section{COMMUNICATION NETWORK OF “BERAS SEHAT INNOVATION”}

\begin{abstract}
This research aims to find out the roles, clicks, and the Beras Sehat Innovation communication network structure in Sudimoro and Daleman Villages, Tulung District, Klaten Regency. The research uses quantitative methods with descriptive analysis, the location is purposively selected, the sampling technique uses the intact sampling system (census), and data analysis uses sociometric analysis. The results showed that: (1) The total role in Sudimoro and Daleman Villages consisted of: opinion leaders, bridges, neglectee, and cosmopolite; (2) Clicks in Sudimoro Village is 17 clicks and in Daleman Village is 21 clicks. Clicks are small groups formed in a communication network; (3) Communication network patterns in Sudimoro and Daleman Villages are patterns of all channels and wheel patterns. The density value in Sudimoro Village is 0.121, and in Daleman Village is 0.127. The diameter of the communication network formed in Sudimoro and Daleman Villages has the same value of 5. The value of connectedness in Sudimoro Village is $41.8 \%$, and in Daleman Village is $88.9 \%$.
\end{abstract}

Keywords: beras sehat, communication network, semi-organic farming.

\begin{abstract}
Abstrak. Penelitian ini bertujuan untuk mengetahui gambaran adanya peranan, klik, dan struktur jaringan komunikasi "Inovasi Beras Sehat" di Desa Sudimoro dan Desa Daleman, Kecamatan Tulung, Kabupaten Klaten. Pendekatan penelitian yang digunakan adalah kuantitatif dengan analisis deskriptif, pemilihan lokasi dilakukan secara purposif, teknik penarikan sampel menggunakan intact sampling system (sensus), dan analisis data dilakukan dengan analisis sosiometri. Hasil penelitian menunjukkan bahwa: (1) Total peranan di Desa Sudimoro dan Desa Daleman terdiri dari: opinion leader, bridge, neglectee, dan cosmopolite; (2) Klik yang terdapat di Desa Sudimoro sebanyak 17 klik dan di Desa Daleman sebanyak 21 klik. Klik merupakan kelompok kecil yang terbentuk dalam jaringan komunikasi; (3) Pola jaringan komunikasi di Desa Sudimoro dan Desa Daleman adalah pola semua saluran dan pola roda. Nilai kepadatan (density) di Desa Sudimoro sebesar 0,121 dan di Desa Daleman sebesar 0,127. Diameter jaringan komunikasi yang terbentuk di Desa Sudimoro dan Desa Daleman memiliki nilai yang sama yaitu 5. Nilai derajat keterhubungan (connectedness) di Desa Sudimoro sebesar 41,8\% dan di Desa Daleman sebesar 88,9\%.
\end{abstract}

Kata kunci: beras sehat, jaringan komunikasi, pertanian semiorganik.

\section{PENDAHULUAN}

Program revolusi hijau yang diadakan pada tahun 1970-an bertujuan untuk meningkatkan produktivitas pertanian, khususnya subsektor pertanian pangan melalui penerapan paket teknologi pertanian modern. Peningkatan produksi pertanian khususnya tanaman pangan merupakan salah satu upaya pemerintah dalam membangun kemandirian dalam sektor pertanian. Sektor pertanian menjadi fokus utama dalam 
menunjang pembangunan karena sektor pertanian merupakan sektor yang memegang peranan penting dalam swasembada pangan nasional (Soetrisno, 2006).

Program yang diterapkan saat itu memberikan hasil yang signifikan terhadap pemenuhan kebutuhan pangan, namun akhirakhir ini muncul berbagai permasalahan lingkungan dan sosial masyarakat akibat adanya program revolusi hijau. Permasalahan lingkungan tersebut antara lain terjadinya pencemaran lingkungan oleh pupuk kimia dan pestisida. Penggunaan bahan kimia yang kurang tepat dan berlebihan yang dilakukan oleh petani menjadi penyebab adanya pencemaran lingkungan dan dampak resistensi pada hama. Dampak buruk pada jangka panjangnya adalah penurunan kualitas hasil panen, lingkungan, dan kualitas kesehatan manusia. Dampak buruk ini sangat sulit untuk dihentikan karena sifat petani yang mulai menggantungkan pada paket-paket teknologi yang dapat digunakan dengan mudah tanpa menghiraukan dampak buruknya bagi lingkungan dan kesehatan (Soetrisno, 2006).

Kesadaran akan dampak buruk revolusi hijau membuat berbagai stakeholder seperti akademisi, pemerintah, Lembaga Swadaya Masyarakat (LSM), dan swasta mulai menyadari tentang pentingnya pertanian berkelanjutan. Menurut Suryana (2005), pertanian berkelanjutan merupakan sistem pertanian yang dapat memanajemen lahan, air, unsur hara, dan hewan secara seimbang sehingga tidak merusak lingkungan, tepat guna secara teknis, layak secara ekonomis, dan diterima secara sosial. Pertanian berkelanjutan berprinsip pada pemenuhan kebutuhan sekarang tanpa mengorbankan pemenuhan kebutuhan generasi yang akan datang. Salah satu inovasi pertanian berkelanjutan adalah pertanian organik.

Pada penelitian terdahulu yang dilakukan oleh (Farkhi, 2013), didapatkan hasil bahwa dalam menyalurkan informasi mengenai budidaya padi organik akan terbentuk kelompok kecil yang disebut klik. Klik dapat terbentuk karena adanya sense of belonging antaranggota kelompok tani. Hubungan antaranggota klik memberi dampak pada keberhasilan tersebarnya informasi dan perubahan perilaku petani dalam menerapkan budi daya padi organik.

Peralihan cara tanam dari konvensional ke sistem pertanian organik memerlukan waktu yang cukup lama. Kondisi lahan pertanian yang saat ini terlanjur tercemar bahan-bahan kimia menjadi salah satu penyebabnya. Kondisi tersebut membuat adanya inovasi baru yang bernama pertanian semiorganik yang bertujuan untuk menunjang pertanian organik di masa depan.

Salah satu lembaga nonpemerintah yang memiliki kepedulian terhadap pengenalan dan penyebaran sistem pertanian semiorganik adalah LSM Gita Pertiwi yang dikenalkan dengan sebutan Beras Sehat. Beras Sehat merupakan nama produk dari hasil padi semiorganik. "Inovasi Beras Sehat" bertujuan untuk meningkatkan pendapatan petani, mengurangi dana pengeluaran pertanian, menjaga kesuburan lahan, meningkatkan produktivitas padi, dan lebih sehat untuk dikonsumsi karena menggunakan pupuk organik dan pestisida nabati serta meminimalisir penggunaan pupuk dan pestisida kimia. Pendampingan Beras Sehat yang dimulai sejak tahun 2013, saat ini telah menghasilkan petani-petani kader yang diharapkan mampu menyebarkan "Inovasi Beras Sehat" kepada petani-petani lain yang belum menerapkan Beras Sehat. Kondisi dari 11 desa dampingan saat ini terdapat satu desa yang masih pada kategori uji coba, yaitu: Desa Sudimoro, Kecamatan Tulung. Status uji coba diberikan kepada desa yang mayoritas petaninya belum mengadopsi inovasi sesuai Standar Operasional Prosedur (SOP). Keputusan petani dalam mengadopsi suatu inovasi dipengaruhi oleh beberapa faktor, salah satunya adalah saluran komunikasi (Rogers \& Kincaid, 1981).

Posisi saluran komunikasi memiliki peran strategis dalam penyebaran informasi, yaitu akan diketahui bagaimana petani saling berkomunikasi dan bertukar informasi. Kelengkapan informasi yang didapatkan oleh petani akan memengaruhi tingkat adopsi petani terhadap "Inovasi Beras Sehat". Seperti yang telah disebutkan bahwa jaringan komunikasi sering digunakan untuk meningkatkan adopsi yang menyeluruh dalam masyarakat (Adger, 2009; Folke et al., 2005; 
Weible, 2005). Hasil sebuah analisis jaringan komunikasi mampu menjawab dari mana perubahan dilakukan dan dari siapa perubahan dimulai agar inovasi dapat diadopsi dengan baik oleh petani.

Kasus keterlambatan adopsi di Desa Sudimoro bisa merefleksikan adanya permasalahan pada jaringan komunikasi yang kurang mendukung. Peneliti juga melihat kondisi di desa lain yang memiliki kondisi homogen dengan Desa Sudimoro untuk memperkuat dugaan tingkat adopsi yang rendah disebabkan oleh jaringan komunikasi yang kurang baik. Desa tersebut adalah Desa Daleman yang memiliki persamaan dengan Desa Sudimoro dalam hal mulainya pendampingan pada tahun 2013 dan terletak pada kecamatan yang sama, namun memiliki kategori adopsi yang lebih berhasil. Penelitian ini bertujuan untuk mengetahui gambaran adanya peranan, klik, dan struktur jaringan komunikasi Beras Sehat di Desa Sudimoro dan Desa Daleman, Kecamatan Tulung, Kabupaten Klaten.

\section{LANDASAN KONSEP}

\section{Jaringan Komunikasi}

Jaringan komunikasi merupakan pola komunikasi umum yang digunakan oleh kelompok atau organisasi dalam mengirim pesan dari satu orang ke orang lain (Wiryanto, 2004). Jaringan komunikasi merupakan kumpulan orang-orang yang memiliki ciri-ciri spesifik sama yang saling berhubungan satu sama lain untuk menjelaskan kebiasaan sosial yang dilakukan oleh kelompok tersebut. Namun demikian bukan berarti suatu jaringan komunikasi hanya dapat terjadi pada orang-orang yang memiliki atribut yang sama saja. Individu dalam jaringan komunikasi tersebut tersebut dikenal dengan nodes. Jaringan komunikasi pada setiap kelompok atau organisasi atau masyarakat yang beragam disebabkan oleh sifat masyarakat, jarak fisik yang jauh dari setiap individunya, dan berbagai peranan dalam struktur sosial (Setyanto, 1993).

Menurut Maryati \& Suryawati (2007), peranan merupakan perilaku individu dalam struktur sosial masyarakat. Pada masyarakat pasti ada peran-peran tertentu seperti pemimpin yang dibuat secara formal maupun terbentuk dengan sendirinya. Peranan dalam jaringan komunikasi yang terbentuk di masyarakat belum tentu sama dengan peranan yang dibentuk secara formal. Peranan seseorang dapat memengaruhi banyaknya informasi yang diterima (Nurhadi, 2017).

Ada beberapa peranan individu dalam jaringan komunikasi. Peranan-peranan tersebut meliputi opinion leader/star, liaison, bridge, isolate (Waldstrøm, 2001; Rogers \& Kincaid, 1981), cosmopolites, gatekeeper, dan neglectee (Rogers \& Kincaid, 1981). Opinion leader merupakan individu yang menjadi pemuka pendapat dan rujukan dalam suatu kelompok. Liaison merupakan orang yang menghubungkan dua atau lebih klik dalam suatu sistem jaringan komunikasi namun ia bukan merupakan anggota dari klik tersebut. Adapun bridge merupakan anggota kelompok atau subkelompok yang berhubungan dengan kelompok atau subkelompok lain, sedangkan isolate adalah individu yang tersisihkan dalam jaringan komunikasi. Cosmopolite merupakan seseorang yang menghubungkan klik dalam kelompok dengan pihak luar. Gatekeeper merupakan seseorang yang bertugas dalam menyaring informasi yang masuk sebelum disebarkan kepada yang lain. Neglectee merupakan mereka yang memilih anggota lain namun tidak dipilih dalam suatu kelompok atau subkelompok.

Pengetahuan tentang siapa saja yang memiliki peran inti dalam jaringan komunikasi akan membantu agent of change atau stakeholder dalam melakukan strategi penyebaran informasi. Seperti menurut Griffin \& Ebert (2006) dengan mengenal orang-orang yang memiliki peran inti pada jaringan komunikasi informal pada perusahaan akan membantu manajer dalam mengontrol informasi yang tersebar pada karyawannya. Jaringan komunikasi dapat digunakan untuk melihat reaksi karyawan terhadap gagasan baru seperti perubahan kebijakan sumber daya manusia. Manajer dapat menggunakan pengetahuan tentang jaringan komunikasi untuk memperoleh informasi yang mengalir pada karyawan dan 
menggunakannya untuk mempertimbangkan pengambilan keputusan ke depannya.

\section{Analisis Jaringan Komunikasi}

Analisis jaringan dapat digunakan untuk mengetahui dan mengukur penyebaran informasi dari media sampai bagaimana informasi tersebut diterima oleh masyarakat atau organisasi. Analisis jaringan komunikasi biasanya digunakan untuk arus informasi yang bersifat inovasi seperti ide, gagasan, dan barang yang baru bagi orang-orang tertentu (Kriyantono, 2010). Analisis jaringan komunikasi merupakan suatu metode penelitian untuk mengetahui bagaimana struktur komunikasi dalam suatu sistem. Analisis jaringan komunikasi mengidentifikasi: (1) Bagaimana peranan yang ada di dalam jaringan komunikasi; (2) Klik dalam jaringan komunikasi; dan (3) Mengukur variasi struktur dalam jaringan komunikasi (Rogers \& Kincaid, 1981).

Peranan individu dalam jaringan komunikasi dapat diukur dengan menggunakan pengukuran level aktor. Menurut Monge (1987) dalam jaringan komunikasi terdapat tiga pengukuran, antara lain level aktor, level kelompok, dan level sistem. Level aktor memiliki pusat perhatian pada peranan dari aktor (node) dalam sebuah jaringan komunikasi. Suatu jaringan komunikasi yang ideal memiliki minimal tiga peranan individu tertentu antara lain peran sebagai pusat komunikasi atau pemuka pendapat, peran sebagai individu yang memiliki kedekatan dengan anggota-anggota kelompok dalam jaringan, dan peran sebagai penjembatan dengan kelompok lain.

Adapun menurut Eriyanto (2014), ukuran yang dipakai dalam level aktor adalah sentralitas (centrality) yang terdiri dari sentralitas tingkatan (degree centrality), sentralitas kedekatan (closeness centrality), sentralitas keperantaraan (betweeness centrality) dan eigen vektor (eigen vector). Level ini dapat digunakan untuk mengetahui siapa aktor yang paling menonjol dan paling menentukan dalam jaringan komunikasi. Sentralitas tingkatan (degree centrality) akan memperlihatkan popularitas individu dalam suatu jaringan.
Eriyanto (2014) menyebutkan bahwa identifikasi klik disebut juga dengan pengukuran level kelompok. Klik yang terbentuk dalam masyarakat disebabkan karena seringnya berkomunikasi dan kemudahan dalam bertemu. Klik-klik dalam jaringan komunikasi memengaruhi adanya penerimaan suatu inovasi baru. Jika inovasi baru tersebut berasal dari anggota klik maka inovasi tersebut akan mudah diterima oleh anggota yang lain.

Menurut Rogers (1983), klik dalam jaringan komunikasi merupakan bagian dari sistem (subsistem) yang anggota-aggotanya relatif lebih sering berkomunikasi dibandingkan dengan anggota-anggota yang lainnya dalam sebuah sistem komunikasi. Terdapat tiga kriteria yang dapat digunakan untuk mengidentifikasi adanya klik dalam jaringan komunikasi. Pertama, setiap klik minimal harus terdiri dari tiga anggota. Kedua, setiap klik minimal harus berjumlah tiga orang dengan memiliki derajat keterhubungan $50 \mathrm{pCt}$ dari hubunganhubungan dalam klik. Ketiga, seluruh anggota klik secara langsung dan tidak langsung saling terhubung dalam rantai hubungan dyadic yang berlangsung secara kontinu dan menyeluruh.

Struktur jaringan komunikasi terbentuk dari individu/node dan link/edge. Menurut Eriyanto (2014) aktor/node merupakan unit analisis yang dapat diidentifikasi sebagai individu, dua orang, subkelompok atau seluruh kelompok dalam sistem. Pernyataan tersebut sama dengan Scott, Baggio \& Cooper (2008) yang menyebutkan bahwa aktor tidak selalu individu namun juga bisa berupa organisasi, negara, perusahaan, lembaga, dan lain sebagainya. Namun pada penelitian ini aktor yang digunakan berupa individu petani. Link/edge merupakan hubungan atau relasi antaraktor yang dilambangkan dengan garis yang menghubungkan aktor yang satu dengan aktor yang lain.

Analisis dalam struktur jaringan digunakan untuk mengetahui pola, ukuran (size), kepadatan (density), resiprositas, diameter, jarak (distance), derajat keterhubungan (connectedness), dan sentralisasi (centralitation) dalam suatu 
jaringan komunikasi. Eriyanto (2014) menjelaskan bahwa analisis tersebut sama dengan analisis level sistem. Ukuran (size) berkaitan dengan jumlah anggota dalam jaringan komunikasi. Jaringan komunikasi yang memiliki ukuran yang kecil akan memiliki intensitas komunikasi yang lebih sering.

Menurut Gonzales (1993) pola-pola dalam jaringan komunikasi dapat penggambaran who say to whom (siapa berbicara kepada siapa) dalam suatu sistem sosial. Menurut Devito dalam Sulistiawati \& P Lubis (2015), ada lima pola jaringan komunikasi kelompok yang juga akan relevan di dalam menganalisis pola jaringan komunikasi di tingkat klik. Kelima pola tersebut yaitu: pola lingkaran, pola roda, pola Y, pola rantai, dan pola semua saluran.

\section{METODE PENELITIAN}

Penelitian jaringan komunikasi Beras Sehat di Kecamatan Tulung, Kabupaten Klaten merupakan penelitian deskriptif dengan pendekatan kuantitatif. Menurut Ardianto (2011) dan Purwanto \& Sulistyastuti (2017), analisis deskriptif tidak bertujuan untuk menguji hipotesis untuk ditarik simpulan yang dapat digeneralisasikan terhadap populasi. Peneliti menganalisis data dengan cara mendeskripsikan atau menggambarkan data melalui bantuan hasil analisis sosiometri dan hasil lapang. Pemilihan lokasi dalam penelitian ini ditentukan secara purposif atau secara sengaja di Desa Sudimoro yang memiliki kategori uji coba dan Desa Daleman yang memiliki kategori sudah menerapkan dan menjadi usaha. Kedua desa tersebut terletak di Kecamatan Tulung. Perbedaan kategori kedua desa tersebut menjadi hal menarik untuk diteliti karena kedua desa tersebut masih dalam satu kecamatan yang sama dan memiliki waktu mulainya pendampingan yang sama yaitu pada tahun 2013 .

Teknik penarikan sampel yang digunakan oleh peneliti adalah metode sampling intact system (sensus), yaitu semua anggota petani Beras Sehat yang berada di Desa Sudimoro dan Desa Daleman dijadikan responden (Rogers \& Kincaid, 1981). Responden tersebut terdiri dari LSM Gita Pertiwi, 20 petani Beras Sehat di Desa Sudimoro, dan 18 petani Beras Sehat di Desa Daleman. Sumber data yang digunakan dalam penelitian ini adalah data primer dan data sekunder. Teknik analisis menggunakan sosiometri dengan bantuan UCINET VI.

\section{HASIL PENELITIAN DAN PEMBAHASAN}

\section{Gambaran Umum Program Beras Sehat di Kecamatan Tulung}

Program Beras Sehat yang diberikan oleh LSM Gita Pertiwi meliputi kegiatan sosialisasi awal, sekolah lapang, dan pendampingan secara berkelanjutan. Sekolah lapang dilakukan dengan cara mengundang minimal tiga orang perwakilan dari setiap desa untuk mengikuti setiap pelatihan. Tiga petani tersebut selanjutnya memiliki tugas untuk menyebarkannya pada petani-petani lain yang ada di desanya. Petani Beras Sehat di Klaten saat ini sudah memiliki komunitas yang bernama KOMPAK (Komunitas Petani Alami Klaten). KOMPAK merupakan wadah bagi petani untuk saling bertukar informasi mengenai Beras Sehat yang akan menampung produksi Beras Sehat dari petani dan merancang pemasaran produk Beras Sehat tersebut.

Kecamatan Tulung memiliki dua desa yang menjadi desa dampingan LSM Gita Pertiwi antara lain Desa Sudimoro dan Desa Daleman. Kedua desa tersebut memiliki kondisi yang berbeda. Tabel 1 menunjukkan persentase jumlah petani yang sudah mengetahui dan mengikuti pelatihan Beras Sehat serta jumlah petani yang sudah menerapkan pertanian Beras Sehat.

\section{Peranan Individu dalam Jaringan Komunikasi "Inovasi Beras Sehat" di Desa Sudimoro}

Peran jaringan komunikasi di Desa Sudimoro antara lain opinion leader, neglectee dan bridge. Opinion leader merupakan pemuka pendapat (Rogers \& Kincaid, 1981). Peran opinion leader dapat 
dimanfaatkan dalam strategi penyebaran inovasi (Valente, 2017).

Peran tersebut dilihat dari jumlah link (jalur) terbanyak yang dimiliki oleh node/aktor. Anak panah dalam link tersebut merupakan anak panah yang menuju petani (indegree) dan keluar dari petani (outdegree). Peran opinion leader di Desa Sudimoro dimiliki oleh $\# \mathrm{E}, \# \mathrm{~F}, \# \mathrm{~L}$, dan $\# \mathrm{U}$ yang terdiri dari ketua, wakil ketua, anggota kelompok tani, dan LSM Gita Pertiwi.

Tabel 1

Jumlah dan Persentase Petani Beras Sehat di Kecamatan Tulung Kabupaten Klaten 2018

\begin{tabular}{|c|c|c|c|c|c|c|}
\hline \multirow[t]{2}{*}{ No } & \multirow{2}{*}{$\begin{array}{c}\text { Nama Kelompok } \\
\text { Tani }\end{array}$} & \multirow[t]{2}{*}{ Anggota } & \multicolumn{2}{|c|}{ Mengikuti Pelatihan } & \multicolumn{2}{|c|}{ Menerapkan } \\
\hline & & & $\begin{array}{l}\text { Jumlah } \\
\text { (orang) }\end{array}$ & $\begin{array}{c}\text { Persentase } \\
(\%)\end{array}$ & $\begin{array}{l}\text { Jumlah } \\
\text { (orang) }\end{array}$ & $\begin{array}{c}\text { Persentase } \\
(\%)\end{array}$ \\
\hline \multicolumn{7}{|c|}{ Desa Sudimoro } \\
\hline 1 & Budi Luhur & 35 & 3 & 8,57 & 0 & 0 \\
\hline 2 & Ngudi Luhur & 36 & 9 & 25 & 1 & 11,11 \\
\hline \multirow[t]{2}{*}{3} & \multirow{2}{*}{$\begin{array}{l}\text { Dadi Luhur } \\
\text { Jumlah Total }\end{array}$} & 39 & 8 & 20,51 & 3 & \multirow{2}{*}{$\begin{array}{c}37,5 \\
20\end{array}$} \\
\hline & & 110 & 20 & 18,18 & 4 & \\
\hline \multicolumn{7}{|c|}{ Desa Daleman } \\
\hline 1 & Sedya Makmur & 30 & 3 & 10 & 2 & 40 \\
\hline 2 & Sedya Maju & 32 & 2 & 6,25 & 2 & 100 \\
\hline \multirow[t]{2}{*}{3} & Tani Mulyo & 33 & 13 & 39,39 & 11 & 84,61 \\
\hline & Jumlah Total & 95 & 18 & 18,95 & 15 & 83,33 \\
\hline
\end{tabular}

Sumber: Wawancara Petani Beras Sehat Kecamatan Tulung (2018).

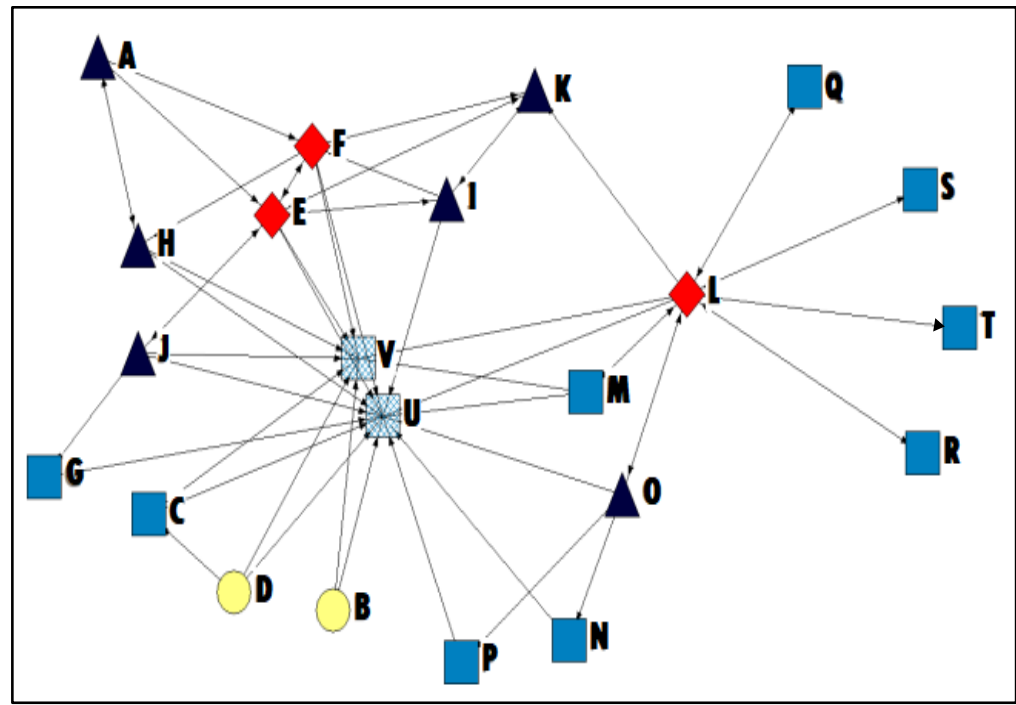

Sumber: Hasil Analisis Data Primer (2018).

Gambar 1. Jaringan Komunikasi Beras Sehat di Desa Sudimoro

Keterangan:

$\begin{aligned} \longrightarrow \quad & =\text { menerima atau memberikan informasi } \\ & =\text { menerima atau memberikan informasi } \\ & =\text { opinion leader, cosmopolite, dan bridge } \\ & =\text { bridge } \\ & =\text { neglectee } \\ & =\text { bukan individu petani di Desa Daleman } \\ & =\text { individu petani di Desa Sudimoro }\end{aligned}$

A, B, C, D, E, F, G, H, K dan T = pengurus kelompok tani

I, J, L, M, N, O, P, Q, R dan S = anggota kelompok tani 
Ketiga petani tersebut berasal dari Kelompok Tani Dadi Luhur dan Ngudi Luhur. Kelompok tani Budi Luhur belum miliki peran opinion leader. Opinion leader banyak melakukan pertukaran informasi dengan petani lain. Opinion leader di Desa Sudimoro memiliki sifat yang ramah, terbuka, dan semangat yang tinggi.

Peran bridge (perantara) ditunjukkan oleh petani $\# \mathrm{~L}, \# \mathrm{E}, \# \mathrm{~F}, \# \mathrm{~K}, \# \mathrm{~J}, \# \mathrm{H}, \# \mathrm{O}, \# \mathrm{~A}$, dan \#I. Petani \#E, \#F, \#K, dan \#H merupakan pengurus kelompok tani sedangkan $\# \mathrm{~L}, \# \mathrm{~J}$, dan \#O merupakan anggota kelompok tani. Brigde memiliki kedekatan dengan opinion leader sehingga informasi yang didapatkan lebih mendalam. Peran brigde dapat membantu opinion leader dalam melakukan penyebaran informasi secara menyeluruh ke seluruh petani di Desa Sudimoro. Namun petani yang memiliki peran brigde di Desa Sudimoro belum semuanya mengadopsi Beras Sehat, sehingga informasi mengenai pertanian Beras Sehat belum menyebar secara lengkap. Peran neglectee dimiliki oleh petani \#B dan \#D. Petani \#B dan \#D merupakan pengurus kelompok tani. Petani \#B dan \#D apabila mendapatkan informasi tidak menyebarkannya kepada petani lain. Hal ini karena mereka merasa ilmu tentang Beras Sehat yang dimiliki masih terbatas dan yakin ada petani lain yang sudah menyebarkan informasi tersebut. Peranan dalam jaringan komunikasi kemudian dianalisis menggunakan perhitungan sentralitas. Perhitungan ini digunakan untuk memperkuat hasil penelitian peranan melalui identifikasi Gambar 1. Kuatnya pengaruh peran opinion leader kepada petani lain dapat dilihat dari nilai sentralitas tingkatan dan sentralitas kedekatan. Apabila nilainya semakin mendekati 1 maka memiliki pengaruh dan kedekatan yang paling tinggi di kelompoknya. Peran bridge yang dilihat dari adanya nilai sentralitas keperantaraan.

\section{Peranan Jaringan Komunikasi "Inovasi Beras Sehat" di Desa Daleman}

Petani-petani di Desa Daleman memiliki beberapa peran dalam proses penyebaran "Inovasi Beras Sehat", di antaranya peran opinion leader, neglectee, cosmopolite, dan bridge. Peran opinion leader dalam jaringan komunikasi di Desa Daleman dimiliki oleh petani \#E, \#H, \#A, \#L, \#J, dan \#W yang terdiri dari satu ketua, dua sekretaris, dua anggota kelompok tani, dan satu LSM Gita Pertiwi. Opinion leader tersebut berasal dari tiga kelompok tani yang berbeda, sehingga dapat diketahui bahwa setiap kelompok tani memiliki minimal satu petani yang bisa dijadikan rujukan dalam mengakses informasi mengenai Beras Sehat.

Peran bridge ditunjukkan oleh petani \#H, \#A, \#L, \#E, \#J, \#G, \#C, \#D, \#K, dan \#I. Petani \#H, \#A, \#E, dan \#G merupakan pengurus kelompok tani. Petani \#L, \#J, \#C, \#D, \#K dan \#I merupakan anggota kelompok tani. Petani bridge di Desa Daleman sudah menerapkan "Inovasi Beras Sehat". Penyebaran informasi yang sudah menyeluruh dan mendalam ke seluruh kelompok tani, hal ini memudahkan petanipetani dalam mengakses informasi mengenai Beras Sehat, sehingga proses adopsi "Inovasi Beras Sehat" sudah banyak diterapkan oleh petani-petani di Desa Daleman. Peran cosmopolite dimiliki oleh petani \#A, \#L, \#J, \#H, \#E, \#I, dan \#K. Petani \#A, \#H, dan \#E merupakan pengurus kelompok tani. Petani $\# \mathrm{~L}, \quad \# \mathrm{~J}$, \#I, dan \#K merupakan anggota kelompok tani. Peran ini memiliki hubungan dengan petani dari desa lain, sehingga informasi yang didapatkan lebih lengkap. Petani di desa lain yang berhasil menerapkan Beras Sehat menjadi salah satu motivasi bagi petani di Desa Daleman dalam menerapkan Beras Sehat. Peran neglectee ditunjukkan oleh petani \#P dan \#Y. Peran neglectee di Desa Daleman ada karena petani tersebut baru mengetahui dan belajar tentang Beras Sehat.

\section{Klik dalam Jaringan Komunikasi "Inovasi Beras Sehat" di Desa Sudimoro}

Informasi mengenai klik dalam jaringan komunikasi akan mempermudah agent of change untuk menganalisis siapa saja petani yang harus didekati agar inovasi tersebut dapat dengan mudah diadopsi oleh petanipetani yang ada di Desa Sudimoro. 
Tabel 2

Perhitungan Sentralitas dalam Jaringan Komunikasi Beras Sehat di Desa Sudimoro

\begin{tabular}{lccc}
\hline \multicolumn{1}{c}{ Aktor } & Sentralitas Tingkatan & N Closeness (Kedekatan) & N Betweenness (Perantara) \\
\hline A (Pengurus) & 0,048 & 0,453 & $\mathbf{1 , 4 2 9}$ \\
B (Pengurus) & 0,036 & 0,348 & 0,000 \\
C (Pengurus) & 0,048 & 0,355 & 0,000 \\
D (Pengurus) & 0,060 & 0,356 & 0,000 \\
E (Pengurus) & $\mathbf{0 , 1 4 3}$ & $\mathbf{0 , 5 2 3}$ & $\mathbf{8 , 0 9 5}$ \\
F (Pengurus) & $\mathbf{0 , 1 0 8}$ & $\mathbf{0 , 5 2 0}$ & $\mathbf{6 , 4 2 9}$ \\
G (Pengurus) & 0,036 & 0,393 & 0,000 \\
H (Pengurus) & 0,072 & 0,472 & $\mathbf{3 , 0 1 6}$ \\
I (Anggota) & 0,072 & 0,497 & $\mathbf{0 , 0 7 9}$ \\
J (Anggota) & 0,060 & 0,475 & $\mathbf{3 , 0 9 5}$ \\
K (Pengurus) & 0,084 & $\mathbf{0 , 5 3 2}$ & $\mathbf{1 2 , 1 4 3}$ \\
L (Anggota) & $\mathbf{0 , 2 1 4}$ & $\mathbf{2 1 , 9 0 5}$ \\
M (Anggota) & 0,060 & $\mathbf{0 , 5 9 4}$ & 0,000 \\
N (Anggota) & 0,036 & 0,380 & 0,000 \\
O (Anggota) & 0,095 & $\mathbf{0 , 5 2 1}$ & $\mathbf{2 , 8 5 7}$ \\
P (Anggota) & 0,036 & 0,380 & 0,000 \\
Q (Anggota) & 0,024 & 0,500 & 0,000 \\
R (Anggota) & 0,024 & 0,500 & 0,000 \\
S (Anggota) & 0,024 & 0,500 & 0,000 \\
T (Anggota) & 0,012 & 0,476 & 0,000 \\
U (LSM) & $\mathbf{0 , 3 6 9}$ & $\mathbf{0 , 8 2 3}$ & 0,000 \\
V (Kelompok Tani) & 0,107 & 0,596 & 0,000 \\
\hline Sumber: Analis &
\end{tabular}

Sumber: Analisis Data Primer (2018).

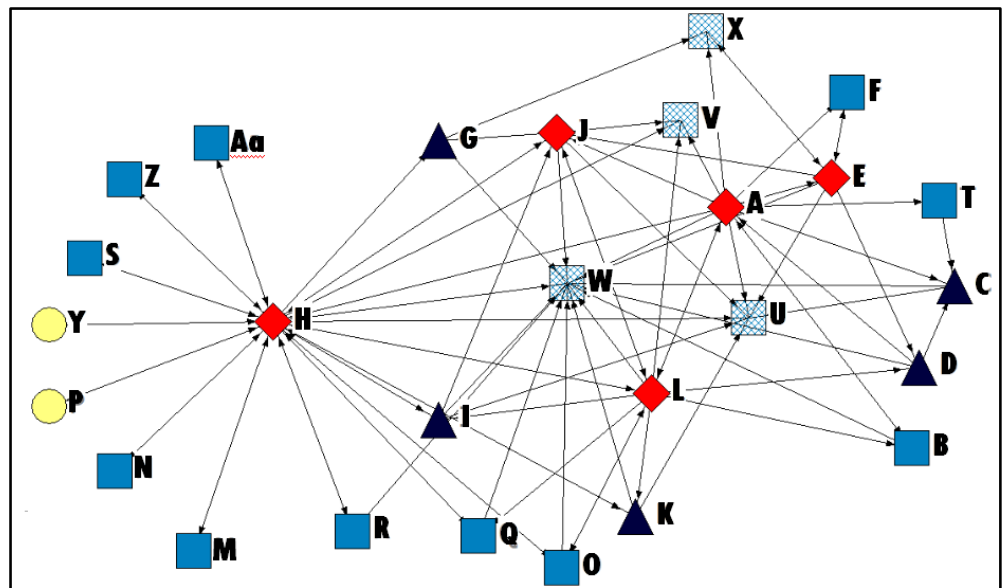

Sumber: Hasil Analisis Data Primer (2018)

Gambar 2. Jaringan Komunikasi Beras Sehat di Desa Daleman

Keterangan:

$\begin{aligned} \longrightarrow & =\text { menerima atau memberikan informasi } \\ & =\text { menerima atau memberikan informasi } \\ & =\text { bridge } \\ & =\text { neglectee } \\ & =\text { bukan individu petani di Desa Daleman } \\ & =\text { individu petani di Desa Sudimoro }\end{aligned}$

A, E, G, dan $\mathrm{H}=$ pengurus kelompok tani

B, C, D, F, I, J, K, L, M, N, O, P, Q, R, S, T, Y, Z, dan Aa = anggota kelompok tani 
Tabel 3

Perhitungan Sentralitas dalam Jaringan Komunikasi Beras Sehat di Desa Daleman

\begin{tabular}{|c|c|c|c|}
\hline Aktor & Sentralitas Tingkatan & N Closeness (Kedekatan) & N Betweenness (Perantara) \\
\hline A (Pengurus) & 0,218 & 1,021 & 27,723 \\
\hline B (Anggota) & 0,064 & 0,744 & 0,000 \\
\hline $\mathrm{C}$ (Anggota) & 0,070 & 0,702 & 0,231 \\
\hline D (Anggota) & 0,051 & 0,757 & 1,462 \\
\hline E (Pengurus) & 0,128 & 0,758 & 11,538 \\
\hline F (Anggota) & 0,064 & 0,612 & 0,000 \\
\hline G (Pengurus) & 0,032 & 0,634 & $\mathbf{3 , 0 7 7}$ \\
\hline H (Pengurus) & 0,395 & 1,175 & 59,492 \\
\hline I (Anggota) & 0,057 & 0,784 & $\mathbf{0 , 0 3 1}$ \\
\hline $\mathrm{J}$ (Anggota) & 0,115 & 0,953 & 6,415 \\
\hline K (Anggota) & 0,051 & 0,777 & $\mathbf{0 , 0 3 1}$ \\
\hline L (Anggota) & 0,160 & 1,040 & 17,923 \\
\hline M (Anggota) & 0,045 & 0,760 & 0,000 \\
\hline N (Anggota) & 0,045 & 0,760 & 0,000 \\
\hline O (Anggota) & 0,064 & 0,832 & 0,000 \\
\hline P (Anggota) & 0,039 & 0,760 & 0,000 \\
\hline Q (Anggota) & 0,057 & 0,770 & 0,000 \\
\hline $\mathrm{R}$ (Anggota) & 0,051 & 0,766 & 0,000 \\
\hline S (Anggota) & 0,045 & 0,760 & 0,000 \\
\hline $\mathrm{T}$ (Anggota) & 0,045 & 0,689 & 0,000 \\
\hline U (Petani luar desa) & 0,051 & 0,648 & 0,000 \\
\hline V (Petani luar desa) & 0,026 & 0,600 & 0,000 \\
\hline W (LSM Gita Pertiwi) & 0,192 & 0,732 & 0,000 \\
\hline $\mathrm{X}$ (Kelompok tani) & 0,032 & 0,673 & 4,692 \\
\hline Y (Anggota) & 0,032 & 0,760 & 0,000 \\
\hline Z (Anggota) & 0,012 & 0,760 & 0,000 \\
\hline Aa (Anggota) & 0,012 & 0,760 & 0,000 \\
\hline
\end{tabular}

Sumber: Analisis Data Primer (2018)

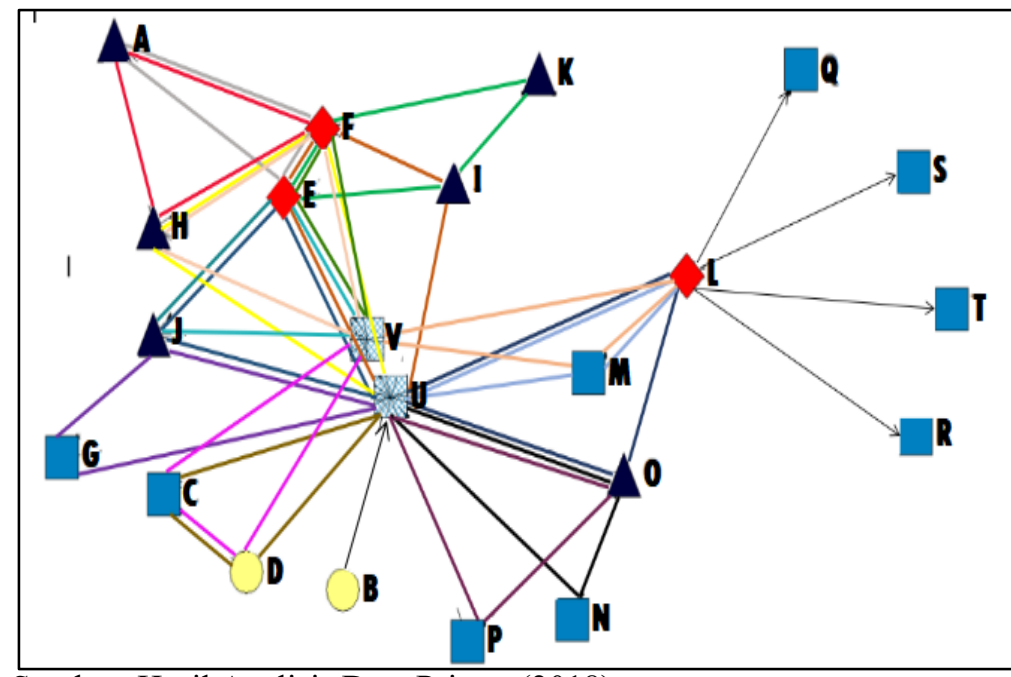

Sumber: Hasil Analisis Data Primer (2018)

Gambar 3. Klik Petani Beras Sehat yang Terbentuk di Desa Sudimoro

Keterangan:

\begin{tabular}{|c|c|c|c|c|c|c|}
\hline Klik $1=$ E-F-I-U & Klik 5 & $=\mathrm{F}-\mathrm{H}-\mathrm{U}$ & Klik 9 & $=\mathrm{O}-\mathrm{P}-\mathrm{U}$ & Klik $13=$ E-J-V & Klik $17=$ F-H-V \\
\hline Klik $2=$ E-J-U & Klik 6 & $=\mathrm{L}-\mathrm{M}-\mathrm{U}$ & Klik 10 & $=\mathrm{E}-\mathrm{F}-\mathrm{I}-\mathrm{K}$ & Klik $14=$ E-F-V & \\
\hline Klik $3=\mathrm{C}-\mathrm{D}-\mathrm{U}$ & Klik 7 & $=\mathrm{L}-\mathrm{O}-\mathrm{U}$ & Klik 11 & $=\mathrm{A}-\mathrm{E}-\mathrm{F}$ & Klik $15=\mathrm{L}-\mathrm{M}-\mathrm{V}$ & \\
\hline Klik $4=$ G-J-U & Klik 8 & $=\mathrm{N}-\mathrm{O}-\mathrm{U}$ & Klik 12 & $=\mathrm{A}-\mathrm{F}-\mathrm{H}$ & Klik $16=\mathrm{C}-\mathrm{D}-\mathrm{V}$ & \\
\hline
\end{tabular}


Anggota klik yang sedikit menunjukkan bahwa antarpetani belum sepenuhnya saling terbuka dengan seluruh petani di Desa Sudimoro. Komunikasi yang terjalin antar petani masih dalam lingkup kecil, bahkan terdapat lima petani yang belum memiliki klik yaitu petani \#B, \#Q, \#R, \#S, dan \#T. Petani \#B belum pernah berkomunikasi secara personal dengan petani lain, ia hanya berkomunikasi dengan LSM Gita Pertiwi dan lewat pertemuan kelompok tani. Petani \#Q, \#R, \#S, dan \#T hanya dapat didekati langsung atau dengan perantara petani \#L. Menurut Weenig \& Midden (1991) suatu informasi akan mudah diterima oleh petani apabila pemberi informasi tersebut adalah orang yang dekat dengan petani atau orang yang dipercaya.

Komunikasi yang kurang luas menyebabkan informasi yang didapatkan oleh petani juga terbatas. Klik yang terbentuk di Desa Sudimoro berjumlah 17. Hal ini menunjukkan bahwa variasi pertukaran informasi antarpetani hanya terdapat 17 variasi. Jika nilai variasi semakin banyak maka kedekatan antar petani juga semakin baik. Penyebaran informasi agar mudah diterima oleh setiap individu petani dapat dilakukan dengan minimal mendekati satu perwakilan dari setiap anggota klik yang terbentuk. Menurut Weenig \& Midden (1991) suatu informasi akan mudah diterima oleh petani apabila pemberi informasi tersebut adalah orang yang dekat dengan petani atau orang yang ia percaya. Penyebaran informasi Beras Sehat dapat dilakukan melalui bantuan opinion leader, namun apabila terdapat petani yang belum bisa dijangkau oleh opinion leader maka penyebaran inovasi dapat dilakukan dengan memilih salah satu orang yang terdapat pada klik yang belum dijangkau oleh opinion leader.

\section{Klik dalam Jaringan Komunikasi "Inovasi Beras Sehat" di Desa Daleman}

Desa Daleman terdapat tujuh petani yang belum memiliki klik yaitu petani \#M,

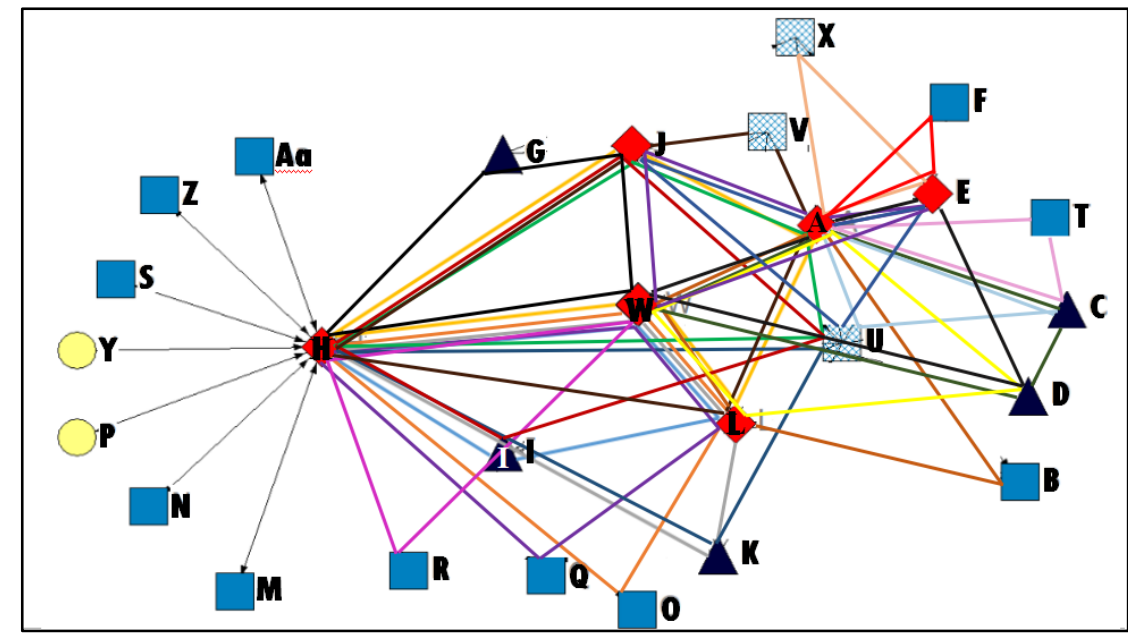

Sumber: Hasil Analisis Data Primer (2018)

Gambar 4. Klik Petani Beras Sehat yang Terbentuk di Desa Daleman

Keterangan:

$\begin{array}{ll}\text { Klik } 8 & =\text { H-I-U-J } \\ \text { Klik } 9 & =\text { A-U-H-J } \\ \text { Klik } 10 & =\text { H-K-U } \\ \text { Klik } 11 & =\text { A-L-H-J-V } \\ \text { Klik } 12 & =\text { A-B-L-W } \\ \text { Klik } 13 & =\text { A-C-D-W } \\ \text { Klik } 14 & =\text { A-C-T }\end{array}$

Klik $8=$ H-I-U-J

Klik 15=A-C-U

Klik 16= A-D-L-W

Klik 17= A-E-D-W

Klik 18= A-E-U-J

Klik 19= A-E-W-J

Klik 20= A-E-F

Klik 21= A-E-X 
\#N, \#P, \#S, \#Y, \#Z, dan \#A. Petanipetani tersebut merupakan petani yang baru dikenalkan dengan pertanian Beras Sehat sehingga belum memiliki klik dengan petani lain. Total jumlah klik 21 dengan anggota maksimal lima orang petani. Anggota klik di Desa Daleman sudah didominasi oleh petani di Desa Daleman itu sendiri. Penyebaran informasi Beras Sehat di Desa Daleman dapat melalui bantuan opinion leader saja, karena dari Gambar 4 dapat diketahui bahwa seluruh petani Beras Sehat di Desa Daleman dapat dijangkau oleh opinion leader.

Nodes/aktor yang memiliki klik terbanyak adalah \#A, \#W, dan \#H. \#A memiliki jumlah klik sebanyak 13 klik. \#W memiliki jumlah klik sebanyak 12 klik. \#H memiliki jumlah klik sebanyak 11 klik. Petani \#A dan \#H merupakan pengurus kelompok tani yang juga memiliki peran sebagai opinion leader, bridge, dan cosmopolite. Sifat \#A dan \#H yang terbuka, ramah, dan aktif dalam kelompok tani menjadikan petanipetani lain merasa dekat dan cocok dengan petani \#A dan \#H. Ketika petani \#A dan \#H mendapatkan ilmu baru mengenai Beras Sehat, maka \#A dan \#H selalu menyebarkannya kepada petani lain. Penyebaran informasi tidak hanya dilakukan melalui pertemuan kelompok tani namun juga melalui kegiatan nonformal seperti saat bertemu di lahan, rumah petani atau warung. Petani \#A dan \#H terkadang juga mengajak petani-petani lain untuk membuat pestisida nabati dan pupuk organik di rumah petani \#A dan \#H.

\section{Struktur Jaringan Komunikasi "Inovasi Beras Sehat" di Desa Sudimoro dan Desa Daleman}

Jaringan komunikasi yang terbentuk di Desa Sudimoro melibatkan 22 node/aktor yang terdiri dari 20 petani Beras Sehat dan dua di antaranya merupakan LSM Gita Pertiwi dan kelompok tani. Di Desa Daleman terdapat 27 node/aktor yang terdiri dari 24 petani di Desa Daleman, tiga aktor di luar Desa Daleman dan satu kelompok tani. Jaringan komunikasi yang terbentuk tersebut selanjutnya dianalisis menggunakan sosiometri untuk menentukan nilai kepadatan, diameter, jarak rata-rata, dan derajat keterhubungan antar-node/aktor.

Pola jaringan saluran dan roda menandakan bahwa sebagian petani sudah saling melakukan perturan informasi dan sebagian lagi masih terpusat pada satu orang. Kepadatan menggambarkan seberapa baik semua aktor berinteraksi satu sama lain. Petani Beras Sehat di Desa Sudimoro dan Desa Daleman memiliki relasi yang berlangsung kurang baik dan kurang menyeluruh. Komunikasi yang terjalin masih terbatas hanya pada beberapa orang saja. Nilai jarak antar petani rata-rata di Desa Sudimoro adalah 2,285 dan Desa Daleman adalah 2,381. Hal ini menunjukkan bahwa jarak petani termasuk pada kategori sangat dekat. Namun hal tersebut berbanding terbalik dengan nilai derajat keterhubungan yang dimiliki oleh Desa Sudimoro. Nilai derajat keterhubungan jaringan komunikasi di Desa Sudimoro sebesar 0,418 atau 41,8 \% yang berarti dalam kategori rendah. Hal ini dikarenakan ada beberapa petani yang tidak melakukan penyebaran informasi Beras Sehat yang diperoleh dan mayoritas petani lebih memilih bertanya kepada LSM Gita Pertiwi mengenai permasalahan Beras Sehat yang ia alami daripada bertukar pengalaman dengan petani lain di Desa Sudimoro. Semakin mendekati satu nilai derajat keterhubungan, maka akan semakin baik proses penyebaran informasi Beras Sehat.

Tabel 4

Hasil Analisis Sosiometri Struktur Jaringan Komunikasi di Desa Sudimoro dan Desa Daleman pada Tahun 2018

\begin{tabular}{lcc}
\hline \multicolumn{1}{c}{ Struktur Jaringan Komunikasi } & Desa Sudimoro & Desa Daleman \\
\hline Pola & Semua saluran dan roda & Semua saluran dan roda \\
Kepadatan & 0,121 & 0,127 \\
Diameter (langkah) & 5,000 & 5,000 \\
Jarak rata-rata (langkah) & 2,285 & 2,381 \\
Derajat keterhubungan & 0,418 & 0,889 \\
\hline
\end{tabular}

Sumber: Analisis Data Primer (2018) 
Tabel 4 menunjukkan bahwa proses penyebaran informasi Beras Sehat di Desa Daleman lebih baik dari Desa Sudimoro. Petani yang belum mengadopsi "Inovasi Beras Sehat" memiliki beberapa pertimbangan di antaranya mayoritas petani di Desa Sudimoro menginginkan adanya peningkatan pendapatan secara nyata dan cepat. Petani terbiasa melakukan sistem jual beli hasil panen dengan cara ditebas oleh tengkulak. Tengkulak berani membayar di awal tanpa mempertimbangkan dengan jenis beras yang ditanam, sehingga petani merasa pendapatannya sama saja. Kondisi ini berbeda dengan petani di Desa Sudimoro yang sudah sukses menerapkan Beras Sehat sesuai dengan SOP, petani tersebut mendapatkan hasil panen yang meningkat dan lebih baik. Petani tersebut terkadang juga menjual hasil panen ke tengkulak dan tengkulak berani membayar lebih tinggi karena hasil panen petani tersebut sangat baik.

Perbedaan kondisi tesebut terjadi karena petani kurang saling terbuka ketika memiliki permasalahan dalam menerapkan Beras Sehat sesuai SOP dan strategi pemasaran. KOMPAK (Komunitas Petani Alami Klaten) dapat menjadi salah satu cara petani untuk menjual hasil panennya. Harga yang ditawarkan Rp200/kg lebih tinggi dari harga pasar. Petani yang belum mengadopsi "Inovasi Beras Sehat" juga beralasan jika prosedur untuk menanam Beras Sehat harus telaten, padahal petani lebih menyukai yang praktis dan tidak ribet. Motivasi petani di Desa Sudimoro untuk menerapkan Beras Sehat perlu ditingkatkan dengan adanya pertukaran informasi dengan petani yang sudah menerapkan Beras Sehat dari dalam desa maupun luar desa.

Mayoritas petani di Desa Daleman sudah menerapkan "Inovasi Beras Sehat". Petani tersebut mau mengadopsi "Inovasi Beras Sehat" karena sudah merasakan keuntungan inovasi, kecocokan inovasi, triabilitas, dan observabilitas. Petani merasakan penerapan padi sehat dapat meningkatkan keuntungan ekonomis karena bulir padi lebih berisi, lebih bagus, rasa beras lebih enak, dan tahan lama sehingga pembeli Beras Sehat lebih banyak dengan harga yang lebih tinggi. Budidaya Beras Sehat bagi petani Desa Daleman mudah untuk diterapkan dan lebih hemat karena bahanbahan yang diperlukan adalah bahan organik yang mudah dicari. Beberapa petani di Desa Daleman memanfaatkan keahlian dalam membuat pestisida nabati untuk dijual ke petani lain. Petani merasa penggunaan pestisida nabati dan vitamin tanaman buatan sendiri lebih baik hasilnya dibandingkan dengan pestisida kimia.

\section{PENUTUP}

\section{Simpulan}

Berdasarkan hasil analisis dan pembahasan yang telah dilakukan mengenai jaringan komunikasi Beras Sehat di Kecamatan Tulung, Kabupaten Klaten, maka diperoleh simpulan antara lain: peranan jaringan komunikasi di Desa Sudimoro antara lain opinion leader, bridge, dan neglectee. Peranan jaringan komunikasi di Desa Daleman antara lain opinion leader, bridge, cosmopolite, dan neglectee. Variasi klik Desa Daleman lebih banyak dari Desa Sudimoro. Semakin banyak nilai variasi klik maka kedekatan antarpetani juga semakin baik.

Pola jaringan komunikasi di Desa Sudimoro dan Desa Daleman adalah semua saluran dan roda. Petani-petani di Desa Daleman sering melakukan interaksi satu sama lain terkait penyebaran "Inovasi Beras Sehat". Petani-petani di Desa Sudimoro jarang melakukan interaksi satu sama lain dalam penyebaran "Inovasi Beras Sehat".

\section{Saran}

Berdasarkan hasil penelitian dan uraian simpulan pada penelitian ini mengenai jaringan komunikasi Beras Sehat di Kecamatan Tulung, Kabupaten Klaten, peranperan yang sudah terbentuk pada petani di Desa Sudimoro dan Desa Daleman dapat lebih dioptimalkan sesuai dengan tugasnya masing-masing. Petani yang memiliki peran seperti opinion leader, bridge, dan cosmpolite dapat dijadikan perwakilan dalam pertemuan pelatihan dari LSM Gita Pertiwi atau stakeholder lain. Klik-klik yang sudah teridentifikasi dapat dimanfaatkan dalam melakukan pendekatan secara perseorangan 
melalui setiap orang yang paling berperan dalam sebuah klik. Pendekatan ini dapat dilakukan oleh peran opinion leader atau bridge atau cosmopolite.

Struktur jaringan dengan pola jaringan komunikasi bentuk roda dan nilai kepadatan yang masih rendah di Desa Sudimoro dan Desa Daleman dapat ditingkatkan dengan adanya komunikasi dua arah antarpetani dan keterbukaan antarpetani (terutama Desa Sudimoro). Nilai diameter dapat diperkecil dengan adanya komunikasi di luar kegiatan pertemuan kelompok, sehingga petani dalam satu desa dapat akrab satu sama lain. Nilai keterhubungan di Desa Sudimoro yang masih tergolong rendah dapat diperbaiki dengan adanya keterbukaan antarpetani terutama bagi petani yang masih tertutup apabila memiliki informasi tentang Beras Sehat dan masalah dengan usaha taninya. Keterbukaan petani dapat dibangun dengan cara dilakukannya pendekatan secara intensif oleh opinion leader atau bridge atau cosmopolite.

\section{DAFTAR PUSTAKA}

Adger, W.N. (2009) Social Capital, Collective Action, and Adaptation to Climate Change. Economic Geography. [Online] 79 (4), 387-404. Available from: doi:10.1111/j.1944-8287.2003.tb00220.x.

Ardianto, E. (2011) Metodologi Penelitian untuk Public Relations Kuantitatif dan Kualitatif. Bandung, Simbiosa Rekatama Media.

Eriyanto (2014) Analisis Jaringan Komunikasi: Strategi Baru Dalam Penelitian Ilmu Komunikasi dan Ilmu Sosial Lainnya. 1st edition. Jakarta, Prenada Media Group.

Farkhi, S. (2013) Analisis Jaringan Komunikasi Dan Adopsi Inovasi Budidaya Padi Organik (Studi Kasus Pada Kelompok Tani Marsudi Mulyo Di Desa Tawangsari, Kecamatan Teras, Kabupaten Boyolali). [Online]. Universitas Sebelas Maret. Available from: https://digilib.uns.ac.id/dokumen/detail/302 98/Analisis-Jaringan-Komunikasi-DanAdopsi-Inovasi-Budidaya-Padi-OrganikStudi-Kasus-Pada-Kelompok-TaniMarsudi-Mulyo-Di-Desa-TawangsariKecamatan-Teras-Kabupaten-Boyolali.

Folke, C., Hahn, T., Olsson, P. \& Norberg, J. (2005) ADAPTIVE GOVERNANCE OF
SOCIAL-ECOLOGICAL SYSTEMS. Annual Review of Environment and Resources. [Online] 30 (1), 441-473. Available from: doi:10.1146/annurev.energy.30.050504.144 511.

Gonzales, H. (1993) Beberapa Mitos Komunikasi dan Pembangunan. In: Amri Jahi (ed.). Komunikasi Massa dan Pembangunan Pedesaan di Negara-Negara Dunia Ketiga. Jakarta, PT Gramedia Pustaka Utama. p.

Griffin, R.W. \& Ebert, R.J. (2006) Bisnis. 8th edition. Jakarta, Erlangga.

Kriyantono, R. (2010) Teknik Praktis Riset Komunikasi. Jakarta, Prenada Media Group.

Maryati, K. \& Suryawati, J. (2007) Sosiologi untuk SMA dan MA. Jakarta, Erlangga.

Monge, P.R. (1987) The Network Level of Analysis. Newbury Parks, California, Sage Publications.

Nurhadi, Z.F. (2017) Teori Komunikasi Kontemporer. Depok, Prenada Media.

Purwanto, E.A. \& Sulistyastuti, D.R. (2017) Metode Penelitian Kuantitatif untuk Administrasi Publik dan Masalah-Masalah Sosial. Yogyakarta, Gava Media.

Rogers, E.M. (1983) Diffusion of Inovations. 4th edition. New York, The Free Press.

Rogers, E.M. \& Kincaid, D.L. (1981) Communication Networks: Toward a New Paradigm for Research. New York, Free Press.

Scott, N., Baggio, R. \& Cooper, C. (2008) Network Analysis and Tourism From Theory to Practice. Toronto, Channel View Publications.

Setyanto, A.E. (1993) Pengaruh Karakteristik Petani dan Keterlibatannya dalam Jaringan Komunikasi dengan Adopsi Paket Teknologi Supra Insus di Desa Pandeyan, Kecamatan Grogol, Kabupaten Sukoharjo, Jawa Tengah. Institut Pertanian Bogor.

Soetrisno, L. (2006) Paradigma Baru Pembangunan Pertanian: Sebuah Tinjauan Sosiologis. Yogyakarta, Kanisius.

Sulistiawati, A. \& P Lubis, D. (2015) ANALISIS JARINGAN SOSIAL DALAM GABUNGAN KELOMPOK TANI (GAPOKTAN) TANI BERKAH. Sodality: Jurnal Sosiologi Pedesaan. [Online] 2 (2). Available from: doi:10.22500/sodality.v2i2.9415.

Suryana, A. (2005) Pembangunan Pertanian Berkelanjutan Andalan Pembangunan Nasional. In: Seminar Sistem Pertanian Berkelanjutan untuk Mendukung 
Pembangunan Nasional. [Online]. 2005 Solo, Universitas Sebelas Maret. p. Available from: http://pse.litbang.pertanian.go.id/ind/pdffile s/Anjak_2005_IV_05.pdf.

Valente, T.W. (2017) Putting the network in network interventions. Proceedings of the National Academy of Sciences. [Online] 114 (36), 9500-9501. Available from: doi:10.1073/pnas.1712473114.

Waldstrøm, C. (2001) Informal Network in Organization. The Aarhus School of Business.

Weenig, M.W. \& Midden, C.J. (1991) Communication network influences on information diffusion and persuasion. Journal of Personality and Social Psychology. [Online] 61 (5), 734-742. Available from: doi:10.1037/00223514.61.5.734.

Weible, C.M. (2005) Beliefs and Perceived Influence in a Natural Resource Conflict: An Advocacy Coalition Approach to Policy Networks. Political Research Quarterly. [Online] 58 (3), 461. Available from: doi: $10.2307 / 3595615$.

Wiryanto (2004) Pengantar Ilmu Komunikasi. Jakarta,

Gravindo. 